\begin{tabular}{|c|c|c|}
\hline $\begin{array}{l}\text { Tender joint count } \\
\text { Swollen joint count } \\
\text { Patient reported outcomes } \\
\text { etc. }\end{array}$ & $\begin{array}{l}\text { Simulations evaluating } \\
\text { expected intra-individual, } \\
\text { intra-observer and } \\
\text { inter-individual variability }\end{array}$ & $\begin{array}{l}\text { High-confidence response } \\
\text { status above } \\
\text { expected variability } \\
\text { in clinical assessments }\end{array}$ \\
\hline Baseline & 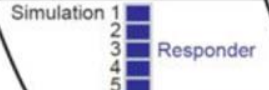 & $\begin{array}{l}\text { High-confidence } \\
\text { responder }\end{array}$ \\
\hline $\begin{array}{l}\text { Follow-up post-treatment } \\
\text { initiation }\end{array}$ & 2000 & $\begin{array}{l}270 \% \text { agreement in } \\
\text { response status } \\
\text { among simulations }\end{array}$ \\
\hline
\end{tabular}

Disclosure of Interests: Vibeke Strand Consultant of: Abbvie, Amgen, Arena, BMS, Boehringer Ingelheim, Celltrion, Galapagos, Genentech/Roche, Gilead, GSK, Ichnos, Inmedix, Janssen, Kiniksa, Lilly, Merck, Novartis, Pfizer, Regeneron, Samsung, Sandoz, Sanofi, Setpoint, UCB, Stanley Cohen: None declared, Lixia Zhang Shareholder of: Scipher Medicine Corporation, Employee of: Scipher Medicine Corporation, Ted Mellors Shareholder of: Scipher Medicine Corporation, Employee of: Scipher Medicine Corporation, Alex Jones Shareholder of: Scipher Medicine Corporation, Employee of: Scipher Medicine Corporation, Johanna Withers Shareholder of: Scipher Medicine Corporation, Employee of: Scipher Medicine Corporation, Viatcheslav Akmaev Shareholder of: Scipher Medicine Corporation, Employee of: Scipher Medicine Corporation DOI: 10.1136/annrheumdis-2021-eular.3341

\begin{tabular}{|l|l}
\hline AB0141 & THE DYNAMICAL TRAJECTORY OF \\
GLUCOCORTICOIDS TAPERING AND \\
DISCONTINUATION IN RHEUMATOID ARTHRITIS \\
PATIENTS COMMENCING GLUCOCORTICOIDS WITH \\
CSDMARDS: A REAL-WORLD DATA FROM 2009 TO 2020
\end{tabular}

W. Xie ${ }^{1}$, H. Huang ${ }^{1}$, Z. Zhang ${ }^{1} .{ }^{1}$ Peking University First Hospital, Department of Rheumatology and Clinical Immunology, Beijing, China

Background: Glucocorticoids (GC) are currently recommended as bridging therapy in combination with csDMARDs in rheumatoid arthritis (RA) and should be tapered as rapidly as clinically feasible for safety concerns about their long-term use [1-3]. Objectives: To unravel the dynamical trajectory and characteristics of GCs tapering and discontinuation in RA patients commencing GCs with concomitant csDMARDs. Methods: We used data from longitudinal real-world TARRA (Treat-to-TARget in RA) cohort in Peking University First Hospital. RA patient who started GCs and contaminant csDMARDs therapy over 1-year follow-up were included. The changes in GCs dose and disease activity in the context of csDMARDs were evaluated. GCs discontinuation rate was analyzed using Kaplan-Meier analysis. The relapse profiles within 6 months after GCs discontinuation were also analyzed.

Results: A total of 207 RA patients were included. During a median follow-up duration of 38.6 months, $124(59.9 \%)$ patients discontinued GC. The median oral prednisolone dose of $10(5-10) \mathrm{mg} / \mathrm{d}$ at initiation was reduced by $50 \%$ in the first 6 months and then more slowly reduced, finally to zero by 48 months. The cumulative probability of GCs discontinuation was $26.6 \%$ at year $1,48.0 \%$ at year 2 , $58.6 \%$ at year 3 , with calculated median time of 27 months (Figure 1). Of the 124 patients who discontinued GCs, add of other csDMARDs or increment of current csDMARDs was required in $29.0 \%$ of them. Approximately half of 124 patients were in clinical remission at the time point of GCs discontinuation. Within 6 months after GCs withdrawal, 79.1\% (91/115) of participants maintained relapse-free.
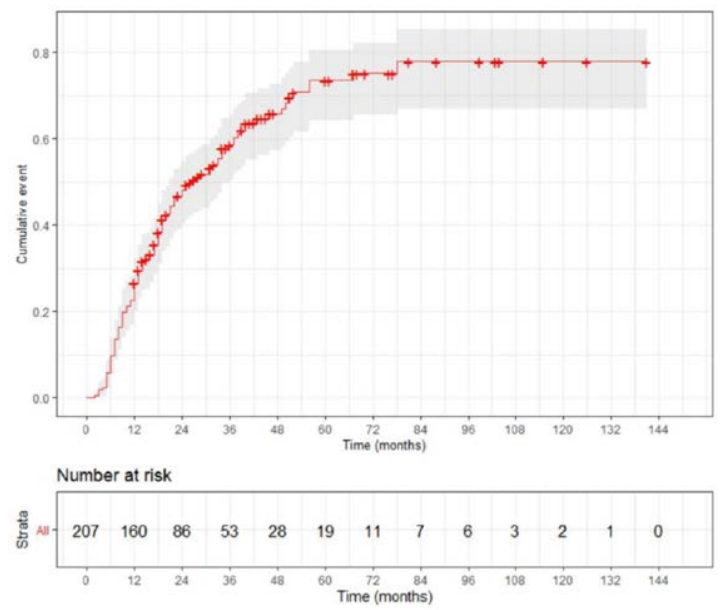

Figure 1. Kaplan-Meier curve with cumulative probability of glucocorticoids discontinuation in RA patients who start glucocorticoids with concomitant csDMARDs during the follow-up period. csDMARDs: conventional synthetic disease modifying antirheumatic drugs.
Conclusion: In RA patients commencing GCs in addition to csDMARDs, GCs are feasibly discontinued with favorable control of disease activity in real-life setting, mostly without short-term flare. Adding targeted therapies are sometimes required to attain GCs discontinuation within the time frame of 3 months in current guidelines. REFERENCES:

[1] Hoes JN, Jacobs JW, Buttgereit F, Bijlsma JW. Current view of glucocorticoid co-therapy with DMARDs in rheumatoid arthritis. Nat Rev Rheumatol. 2010 Dec;6(12):693-702. doi: 10.1038/nrrheum.2010.179.

[2] Smolen JS, Landewé RBM, Bijlsma JWJ, et al. EULAR recommendations for the management of rheumatoid arthritis with synthetic and biological disease-modifying antirheumatic drugs: 2019 update. Ann Rheum Dis. 2020 Jun;79(6):685-699. doi: 10.1136/annrheumdis-2019-216655

[3] Conn DL. The Story Behind the Use of Glucocorticoids in the Treatment of Rheumatoid Arthritis. Semin Arthritis Rheum. 2020 Dec 17;51(1):15-19. doi: 10.1016/.semarthrit.2020.09.016.

Disclosure of Interests: None declared

DOI: 10.1136/annrheumdis-2021-eular.3414

\section{AB0142 SOCIOECONOMIC STATUS (SES) AND MEDICATION USE IN RHEUMATOID ARTHRITIS (RA): A SCOPING REVIEW}

O. Russell ${ }^{1}$, S. Lester ${ }^{1}$, R. Black ${ }^{1,2,3}$, C. Hill ${ }^{1,2,3} .{ }^{1}$ The University of Adelaide, Adelaide Medical School, Adelaide, Australia; ${ }^{2}$ Royal Adelaide Hospital, Rheumatology Unit, Adelaide, Australia; ${ }^{3}$ The Queen Elizabeth Hospital, Rheumatology Unit, Woodville South, Australia

Background: Socioeconomic status (SES) influences disease outcomes in rheumatoid arthritis (RA) patients. $(1,2)$ Differences in medication use could partly explain this association. (3) A scoping review was used to identify research conducted on this topic and determine what knowledge gaps remain.

Objectives: To determine what research has been conducted on this topic, how this research has defined SES and medication use, and establish what knowledge gaps remain.

Methods: MEDLINE, EMBASE and PsychInfo were searched from their inception until May 2019 for studies which assessed SES and medication use as outcome variables. Studies were included if they measured medication use and incorporated an SES measure as a comparator variable.

SES was defined using any of the "PROGRESS" framework variables (4) including patients' stated gender, age, educational attainment, employment, occupational class, personal income, marital status, health insurance coverage, area- (neighbourhood) level SES, or patients' stated race and/or ethnicity. Medication use was broadly defined as either prescription or dispensation of a medicine, medication adherence, or delays in treatment. Data was extracted on studies' primary objectives, measurement of specific SES measures, patients' medication use, and whether studies assessed for differences in patients' medication use according to SES variables.

Results: 1464 studies were identified by this search from which 74 studies were selected for inclusion, including 52 published articles. Studies' publication year ranged from 1994-2019, and originated from 20 countries; most commonly from the USA. Studies measured a median of 4 SES variables (IQR 3-6), with educational achievement, area level SES and race/ethnicity the most frequently recorded.

Likelihood of disease modifying antirheumatic drug (DMARD) prescription was the most frequent primary objective recorded.

$96 \%$ of studies reported on patients' use of DMARDs, with glucocorticoids and analgesics being reported in fewer studies $(51 \%$ and $23 \%$ respectively.)

Most included studies found at least one SES measure to be significantly associated with differences in patients' medication use. In some studies, however, this result was not necessarily drawn from the primary outcome and therefore may not have been adjusted for covariates.

$70 \%$ of published studies measuring patients' income ( $n=14$ of 20 ) and $58 \%$ of those that measured race/ethnicity $(n=14$ of 24$)$ documented significant differences in patients' medication use according to these SES variables, although the direction of this effect - whether it led to 'greater' or 'lesser' medication use - varied between studies.

Conclusion: Multiple definitions of SES are used in studies of medication use in RA patients. Despite this, most identified studies found evidence of a difference in medication use by patient groups that differed by an SES variable, although how medication use differed was found to vary between studies. This latter observation may relate to contextual factors pertaining to differences in countries' healthcare systems. Further prospective studies with clearly defined SES and medication use measures may help confirm the apparent association between SES and differences in medication use. REFERENCES:

[1] Jacobi CE, Mol GD, Boshuizen HC, Rupp I, Dinant HJ, Van Den Bos GA. Impact of socioeconomic status on the course of rheumatoid arthritis and on related use of health care services. Arthritis Rheum. 2003;49(4):567-73.

[2] ERAS Study Group. Socioeconomic deprivation and rheumatoid disease: what lessons for the health service? ERAS Study Group. Early Rheumatoid Arthritis Study. Annals of the rheumatic diseases. 2000;59(10):794-9. 